\title{
Effects of dietary supplementation with oridonin on the growth performance, relative organ weight, lymphocyte proliferation, and cytokine concentration in broiler chickens
}

\author{
Qiu Jue $\mathrm{Wu}^{1,2,3}$, Xiao Chuan Zheng ${ }^{1}$, Tian Wang ${ }^{1 *}$ (1) and Tie Ying Zhang ${ }^{2}$
}

\begin{abstract}
Background: The present study was conducted to investigate the effects of oridonin (ORI) on growth performance, relative organ weight, lymphocyte proliferation, phagocytic function of neutrophils, and cytokine concentration in broiler chickens. A total of 240 one-day-old Arbor Acres male broilers were randomly assigned to four treatments with six replicate pens of 10 broiler chickens per pen. Broiler chickens were fed diets based on four levels of dietary ORI $(0,50$, 80 and $100 \mathrm{mg} / \mathrm{kg}$ ) for a 42-d feeding trial. The experimental diets were fed in three phases: 1 to $14 \mathrm{~d}, 15$ to $28 \mathrm{~d}$ and 29 to $42 \mathrm{~d}$.

Results: The results indicated that ORI has no influence on the growth performance $(P>0.05)$. However, ORI increased the relative weights of spleen and bursa, the number of proliferation peripheral blood $T$ and B lymphocytes, the phagocytic rate of neutrophils, as well as the Interleukin-2 (IL-2), Interleukin-4 (IL-4) and tumor necrosis factor-a (TNF-a) serum concentrations in serum in broilers at days 14,28 and $42(P<0.05)$.

Conclusions: In conclusion, ORI can enhance immune function and resistance to disease in broiler chickens by stimulating $T$ and $B$ lymphocyte formation, division, and proliferation, as well as the modulation of Th1/Th2 cytokine secretion profiles.
\end{abstract}

Keywords: Oridonin, Lymphocyte proliferation, Phagocytisis of neutrophils, Cytokine, Broiler

\section{Background}

With the rapid development of the poultry industry, high stocking densities and high yield requirements have induced broiler chickens to have higher immunological stress reactions and increased the potential risk of disease outbreaks in commercial poultry flocks. Immunological stress may cause the loss of immune homeostasis and trigger immunological stress responses, followed by enteritis, mortality, welfare problems and economic losses due to production losses and costs for treatment or prevention. Thus, exploring alternative substances

\footnotetext{
* Correspondence: hdzwaj@163.com

${ }^{1}$ College of Animal Science and Technology, Nanjing Agricultural University, No. 6, Tongwei Road, Xuanwu District, Nanjing 210095, Jiangsu, People's Republic of China

Full list of author information is available at the end of the article
}

and strategies to modulate the broiler immune system is of great significance.

Oridonin (ORI) as a multifunctional compound initially isolated from Isodon rubescens (a. k. a. "Rabdosia rubescens", traditional Chinese medicine name "Donglingcao"), is now widely used as a drug for humans. Correspondingly, it has been proven to possess considerable anticancer, antioxidation, and anti-inflammatory properties, it has been used to restrain bacterial growth and viral reproduction, detoxify, reduce pain, invigorate the stomach and protect other organs in Asian countries for hundreds of years [1-3].

ORI is considered to be an immune-enhancing dietary supplement, which not only improves phagocytes and inflammatory cytokine production but also exerts 
immuno-modulating functions for the body. Several studies have provided evidence that ORI is involved in inflammation and antitumor activities [4]. Studies in broilers showed that dietary ORI supplementation decreases expression of the proinflammatory cytokine in the LPS-induced inflammatory response [5]. It has been well documented that the inclusion of oridonin in rat diets can promote the development of immune organs, stimulate organ immunoglobulin secretion, and prohibit the colonization of Escherichia coli and Salmonella. Additionally, ORI component supplementation has been reported to enhance $\mathrm{T}$ lymphocyte responses in vivo [6].

It is well known that immune-modulating nutrients can be harmful if not utilized in moderation. However, whether oridonin could be used as an anti-inflammatory treatment, and the mechanisms underlying its antiinflammatory activity, remains unknown. Therefore, the following study was conducted to further investigate the effect of dietary supplementation of ORI on growth performance, relative organ weights, lymphocyte proliferation, and cytokine concentration in broiler chickens and to gain a better understanding of the application of dietary ORI supplementation in the poultry industry for improving the health and preventing infectious diseases among broilers.

\section{Methods}

\section{Animals, study design and diets}

A total of 240 one-day-old male broiler chickens (Arbor Acres) were obtained from a commercial hatchery (Broiler Breeder of South Khorasan Complex Productive Co., Iran). All birds were weighed individually and were randomly assigned to four dietary treatment groups in a completely randomized design, each of which included 6 replicates with 10 birds per replicate. The 4 treatment groups were as follows: the control group, in which birds were received the basal diet. The ORI treatment groups, the basal diet was supplemented with oridonin (ORI) at $50 \mathrm{mg} / \mathrm{kg}, 80 \mathrm{mg} / \mathrm{kg}$ or $100 \mathrm{mg} / \mathrm{kg}$ (O1, O2 and O3 treatments), respectively. The trial lasted 42 days. Chicks were housed in three-story step cages $(2 \mathrm{~m} \times 1.4 \mathrm{~m} \times 0.38 \mathrm{~m})$ in an environmentally controlled room. The rearing room temperature and lighting cycle were provided according to procedure of broiler rearing and management during the period of experiment. The birds were fed the experimental diets in three phases 1 to $14 \mathrm{~d}, 14$ to $28 \mathrm{~d}$ and 28 to $42 \mathrm{~d}$. The basal diets were of the maize-soybean-type. The experimental diets were formulated based on the National Research Council (1994) [7] to meet or exceed the nutrient requirements for broiler chickens (Table 1). Fresh diets were prepared once a week and were stored in sealed bags at $4{ }^{\circ} \mathrm{C}$. Feed and water were provided ad libitum throughout the experiment.
Table 1 Ingredients and chemical composition of diets used during starter (1-14 d of age), grower (15-28 d of age), and finisher periods (29-42 d of age)

\begin{tabular}{|c|c|c|c|}
\hline Ingredients (g/kg) & $1-14 d$ & $15-28$ & $29-42 d$ \\
\hline Corn & 428 & 459 & 476 \\
\hline Soybean meal (43\%, crude protein) & 365 & 250 & 203 \\
\hline Wheat & 130 & 220 & 250 \\
\hline Soybean oil & 17 & 8.5 & 10 \\
\hline Corn gluten meal & 20 & 0 & 0 \\
\hline Canola meal & 0 & 25.5 & 25 \\
\hline Na chloride & 2.3 & 3 & 2.8 \\
\hline Dicalcium phosphate & 15 & 12.5 & 11 \\
\hline Na bicarbonate & 2.4 & 0.9 & 1 \\
\hline Ca carbonate & 10.8 & 10.4 & 11 \\
\hline DL-Methionine & 2.7 & 1.5 & 1.5 \\
\hline L-Lysine. $\mathrm{HCl}$ & 2.2 & 0.6 & 1.1 \\
\hline Premix $^{a}$ & 2 & 2 & 2 \\
\hline Multi-enzyme & 0.3 & 0.3 & 0.3 \\
\hline Phytase & 0.3 & 0.3 & 0.3 \\
\hline Bentonite & 0.0 & 5.5 & 5 \\
\hline Prebiotics & 2 & 0 & 0 \\
\hline Total & 1,000 & 1,000 & 1,000 \\
\hline \multicolumn{4}{|l|}{ Calculation of nutrients (g/kg) } \\
\hline Apparent metabolism energy (MJ/kg) & 12.5 & 12.7 & 12.9 \\
\hline Crude protein & 222 & 201 & 193 \\
\hline Calcium & 9.7 & 9.3 & 9.0 \\
\hline Available phosphorus & 4.7 & 4.5 & 4.2 \\
\hline Lysine & 13.8 & 11.3 & 11.0 \\
\hline Methionine & 6.0 & 4.7 & 4.3 \\
\hline Methionine + cysteine & 8.1 & 7.6 & 7.1 \\
\hline
\end{tabular}

apremix provided per kg of diet: Vitamin A (transretinyl acetate), 10,000 IU; Vitamin $\mathrm{D}_{3}$ (cholecalciferol), $3000 \mathrm{IU}$; Vitamin $\mathrm{E}$ (all-rac- $\alpha$-tocopherolacetate), $30 \mathrm{IU}$; menadione, $1.3 \mathrm{mg}$; thiamine $2.2 \mathrm{mg}$; riboflavin, $8 \mathrm{mg}$; nicotinamide, $40 \mathrm{mg}$; choline chloride, $600 \mathrm{mg}$; calcium pantothenate, $10 \mathrm{mg}$; pyridoxine. $\mathrm{HCl}$, $4 \mathrm{mg}$; biotin, $0.04 \mathrm{mg}$; folic acid, $1 \mathrm{mg}$; vitamin $\mathrm{B}_{12}$ (cobalamine), $0.013 \mathrm{mg}$; Fe (from ferrous sulfate), $80 \mathrm{mg}$; Cu (from copper sulfate), $8 \mathrm{mg} ; \mathrm{Mn}$ (from manganese sulfate), 110 mg; Zn (Bacitracin Zn), 65 mg; iodine (from calcium iodate), $1.1 \mathrm{mg}$; Se (from sodium selenite), $0.3 \mathrm{mg}$

\section{Sample collection and procedures}

In this experiment, the pen was the experimental unit, and data on body weight and feed intake were measured weekly, those data were used to calculate weight gain (WG), feed intake (FI) and feed conversion ratio (FCR).

At 14, 28 and 42 days of age, twelve broilers from each treatment were used for sample collecting. The birds were weighed, and blood samples were collected and separated by centrifugation at $3000 \times \mathrm{g}$ for $15 \mathrm{~min}$ at $4{ }^{\circ} \mathrm{C}$. Serum samples were frozen at $-80{ }^{\circ} \mathrm{C}$ until ELISA analysis. Then, all of the 24 broilers were sacrificed by exsanguination. After decapitation, internal organs (liver, spleen, pancreas, gizzard and bursa) were excised 
and weights of these organs were measured. Organ indexes were calculated as weight of organ $(\mathrm{g}) / 100 \mathrm{~g}$ body weight.

\section{Measurement of lymphocyte proliferation by the MTT method} Take fresh anticoagulated blood from the wing vein on $\mathrm{d}$ 14, 28 and 42 to a heparinized centrifuge tube.The peripheral blood lymphocytes were obtained using lymphocyte separation medium. Then cells were washed, resuspended, seeded and cultured according the MTT method, respectively. Subsequently, the number of proliferation peripheral blood $\mathrm{T}$ and $\mathrm{B}$ lymphocyte were calculated using the following equation: $\mathrm{SI}=\mathrm{OD} 570(\mathrm{~T} / \mathrm{B}$ lymphocyte proliferation group)/OD570 (control group).

\section{Isolation and examination of the phagocytic function of neutrophils}

Neutrophils of broiler blood were isolated using the Histopaque (Sigma-Aldrich) separating medium. The cells were centrifuged, withdrawn, washed and detached in plastic tubes, respectively. Then, the pellet were resuspended in the Hank's medium.

Cells were counted using the phase-contrast microscopy at 40 .

Hank's cellular suspension $\left(5 \times 10^{5}\right.$ neutrophils $\left./ \mathrm{mL}\right)$ were then put into the wells of plastic macrophage migration, and discarded the supernatant. The cells were stained with acridine orange. Neutrophils was phagocytosed and dead bacteria (orange) were determined. The number of particles ingested per 100 neutrophils was expressed as the phagocytosis index (PI). The percentage of cells that had phagocytosed was expressed as the phagocytosis percentage (PP).

ELISA for the determination of TNF- $a$, IL-2 and IL-4 production The serum concentrations of TNF- $\alpha$, IL-2 and IL-4 were determined using commercial chicken ELISA kits (Adlitteram Diagnostic Laboratories, San Diego, CA, USA).

\section{Statistical analysis}

Variance analyses were done using the General Linear Model procedure of the Statistical Package for Social Sciences 20.0 (SPSS Inc., Chicago, IL, USA) as a completely randomized design. The significant differences among different treatment means were separated using the Duncan's new multiple range test at $P \leq 0.05$.

\section{Results}

Growth performance

All growth performance parameters were not influenced $(P>0.05)$ by dietary ORI levels (Table 2$)$.
Table 2 Effects of ORI on the growth performance of broilers

\begin{tabular}{|c|c|c|c|c|c|c|}
\hline \multirow[t]{2}{*}{ Items } & \multicolumn{4}{|c|}{ Diet Treatments ${ }^{a}$} & \multirow[t]{2}{*}{$\mathrm{SEM}^{\mathrm{b}}$} & \multirow[t]{2}{*}{$P$-Value } \\
\hline & $\overline{\mathrm{CON}}$ & 01 & $\mathrm{O} 2$ & $\mathrm{O} 3$ & & \\
\hline \multicolumn{7}{|l|}{$1-14 d$} \\
\hline $\mathrm{Fl}^{\mathrm{c}}(\mathrm{g} / \mathrm{d})$ & 41.8 & 41.5 & 41.4 & 41.0 & 0.1 & 0.20 \\
\hline$W G^{c}(g / d)$ & 30.1 & 30.3 & 30.4 & 31.1 & 0.2 & 0.37 \\
\hline $\mathrm{FCR}^{c}$ & 1.39 & 1.37 & 1.36 & 1.32 & 0.02 & 0.17 \\
\hline \multicolumn{7}{|l|}{$14-28 d$} \\
\hline$F l^{c}(g / d)$ & 127 & 126 & 126 & 125 & 1.3 & 0.24 \\
\hline$W G^{c}(g / d)$ & 81.4 & 82.4 & 84.0 & 83.9 & 1.2 & 0.10 \\
\hline $\mathrm{FCR}^{\mathrm{c}}$ & 1.56 & 1.53 & 1.50 & 1.49 & 0.04 & 0.31 \\
\hline \multicolumn{7}{|l|}{$28-42 d$} \\
\hline $\mathrm{Fl}^{\mathrm{c}}(\mathrm{g} / \mathrm{d})$ & 210 & 209 & 209 & 207 & 1.7 & 0.19 \\
\hline$W G^{c}(g / d)$ & 99.5 & 100 & 100.5 & 101.5 & 1.0 & 0.14 \\
\hline$F C R^{c}$ & 2.11 & 2.09 & 2.08 & 2.04 & 0.06 & 0.21 \\
\hline \multicolumn{7}{|l|}{$1-42 d$} \\
\hline $\mathrm{Fl}^{\mathrm{c}}(\mathrm{g} / \mathrm{d})$ & 127 & 126 & 125 & 123 & 1.0 & 0.33 \\
\hline$W G^{c}(g / d)$ & 69.4 & 69.2 & 69.4 & 69.1 & 0.9 & 0.21 \\
\hline$F C R^{c}$ & 1.83 & 1.82 & 1.80 & 1.78 & 0.02 & 0.25 \\
\hline
\end{tabular}

${ }^{\mathrm{a}}$ Control $=$ basal diet; $\mathrm{O} 1, \mathrm{O} 2$, and $\mathrm{O} 3$ groups $=$ basal diet with 50,80 , and $100 \mathrm{mg} / \mathrm{kg}$ ORl, respectively

${ }^{\mathrm{b}}$ Standard error of the mean based on pooled estimate of variation

${ }^{c} \mathrm{FI}=$ feed intake; $\mathrm{WG}=$ weight gain; $\mathrm{FCR}=$ feed conversion ratio

\section{Relative organ weight}

Compared with the control, broilers fed basal diet supplemented with ORI (Table 3) significantly increased relative weights of spleen and bursa at day 14, 28 and 42 $(P<0.05)$. However, inclusion of ORI did not have a significant effect on the relative weights of thymus, liver, pancreas or gizzard $(P>0.05)$.

\section{Proliferation peripheral blood T and B lymphocyte}

As shown in Table 4, inclusion of ORI in the diet significantly increased the number of proliferation peripheral blood $\mathrm{T}$ and $\mathrm{B}$ lymphocytes at day 14, 28 and 42 when compared with the control group $(P<0.05)$.

\section{Phagocytic rate and phagocytic index of neutrophil}

Dietary ORI supplementation had no significant effect on the phagocytic index of neutrophils on either day 14 or 28 (Table 5). However, dietary ORI supplementation significantly increased the phagocytic index of neutrophils on day $42(P<0.05)$. Dietary ORI supplementation significantly increased the phagocytic rate of neutrophils of broilers on days 14,28 and $42(P<0.05)$.

\section{Cytokine levels in serum}

As showen in Table 6, compared with the basal diet, IL-2, IL-4 and TNF-a levels in the serum of broilers were markedly increased by the ORI on day 14,28 and $42(P<0.05)$. 
Table 3 Effects of ORI on weight of internal organs of broiler chickens ( $\mathrm{g} / 100 \mathrm{~g}$ body weight of bird)

\begin{tabular}{|c|c|c|c|c|c|c|}
\hline \multirow[t]{2}{*}{ Items } & \multicolumn{4}{|c|}{ Diet Treatments ${ }^{1}$} & \multirow[t]{2}{*}{$\mathrm{SEM}^{2}$} & \multirow[t]{2}{*}{$P$-Value } \\
\hline & $\mathrm{CON}$ & O1 & $\mathrm{O} 2$ & $\mathrm{O} 3$ & & \\
\hline \multicolumn{7}{|l|}{$14 \mathrm{~d}$} \\
\hline Liver & 2.73 & 2.76 & 2.74 & 2.79 & 0.24 & 0.333 \\
\hline Spleen & $0.08 b$ & $0.13 a$ & $0.15 a$ & $0.14 a$ & 0.02 & 0.123 \\
\hline Pancreas & 0.42 & 0.40 & 0.38 & 0.39 & 0.67 & 0.231 \\
\hline Gizzard & 2.15 & 2.25 & 2.34 & 2.38 & 0.23 & 0.164 \\
\hline Bursa & $0.12 b$ & $0.16 a$ & $0.17 a$ & $0.17 a$ & 0.01 & 0.109 \\
\hline \multicolumn{7}{|l|}{$28 d$} \\
\hline Liver & 2.87 & 2.95 & 3.02 & 3.08 & 0.24 & 0.233 \\
\hline Spleen & $0.10 \mathrm{~b}$ & $0.17 a$ & $0.17 a$ & $0.18 a$ & 0.01 & 0.03 \\
\hline Pancreas & 0.37 & 0.37 & 0.36 & 0.35 & 0.04 & 0.671 \\
\hline Gizzard & 1.67 & 1.92 & 1.73 & 1.78 & 0.23 & 0.254 \\
\hline Bursa & $0.14 b$ & $0.18 a$ & $0.19 a$ & $0.20 \mathrm{a}$ & 0.01 & 0.214 \\
\hline \multicolumn{7}{|l|}{$42 d$} \\
\hline Liver & 3.50 & 3.46 & 3.35 & 2.84 & 0.21 & 0.27 \\
\hline Spleen & $0.12 b$ & $0.21 a$ & $0.22 a$ & $0.23 a$ & 0.01 & 0.03 \\
\hline Pancreas & 0.29 & 0.28 & 0.26 & 0.27 & 0.03 & 0.150 \\
\hline Gizzard & 1.05 & 1.25 & 1.20 & 1.21 & 0.21 & 0.124 \\
\hline Bursa & $0.16 b$ & $0.20 \mathrm{~b}$ & $0.20 \mathrm{~b}$ & $0.21 \mathrm{a}$ & 0.13 & 0.104 \\
\hline
\end{tabular}

${ }^{1}$ Control = basal diet; $\mathrm{O} 1, \mathrm{O} 2$, and $\mathrm{O} 3$ groups = basal diet with 50, 80, and $100 \mathrm{mg} / \mathrm{kg}$ ORI, respectively

${ }^{2}$ Standard error of the mean based on pooled estimate of variation

${ }^{a-b}$ Means within the same row that do not share a common superscript are significantly different $(P<0.05) ; n=8$

\section{Discussion}

The literature suggests that oridonin could increase the average daily gain of murine injected with LPS, which was probably ascribed to the anti-inflammatory potential of oridonin by suppressing the production of proinflammatory cytokines (Xu et al. 2009) [8]. However,

Table 4 Effects of ORI on the number of proliferation peripheral blood T and B lymphocyte of broiler chickens (\%)

\begin{tabular}{|c|c|c|c|c|c|c|}
\hline \multirow[t]{2}{*}{ Items } & \multicolumn{4}{|c|}{ Diet Treatments $^{1}$} & \multirow[t]{2}{*}{ SEM $^{2}$} & \multirow[t]{2}{*}{ P-Value } \\
\hline & $\mathrm{CON}$ & 01 & $\mathrm{O} 2$ & $\mathrm{O} 3$ & & \\
\hline
\end{tabular}

\begin{tabular}{|c|c|c|c|c|c|c|}
\hline \multicolumn{7}{|c|}{ T lymphocyte } \\
\hline $14 \mathrm{~d}$ & $0.13 b$ & $0.29 a$ & $0.33 a$ & $0.36 a$ & 0.09 & 0.031 \\
\hline $28 d$ & $0.13 b$ & $0.32 \mathrm{a}$ & $0.36 a$ & $0.38 a$ & 0.04 & 0.027 \\
\hline $42 d$ & $0.51 b$ & $0.71 a$ & $0.77 a$ & $0.76 a$ & 0.11 & 0.031 \\
\hline \multicolumn{7}{|c|}{ B lymphocyte } \\
\hline $14 \mathrm{~d}$ & $0.13 b$ & $0.27 a$ & $0.31 a$ & $0.37 a$ & 0.05 & 0.043 \\
\hline $28 \mathrm{~d}$ & $0.16 b$ & $0.24 a$ & $0.22 a$ & $0.26 a$ & 0.03 & 0.024 \\
\hline $42 d$ & $0.14 b$ & $0.47 a$ & $0.46 a$ & $0.50 \mathrm{a}$ & 0.02 & 0.032 \\
\hline
\end{tabular}

${ }^{1}$ Control = basal diet; 01, O2, and 03 groups = basal diet with 50, 80, and $100 \mathrm{mg} / \mathrm{kg}$ ORI, respectively

${ }^{2}$ Standard error of the mean based on pooled estimate of variation

a-b Means within the same row that do not share a common superscript are significantly different $(P<0.05) ; n=8$
Table 5 Effects of ORI on phagocytic rate and phagocytic index of neutrophil of broiler chickens

\begin{tabular}{|c|c|c|c|c|c|c|}
\hline \multirow[t]{2}{*}{ Items } & \multicolumn{4}{|c|}{ Diet Treatments $^{1}$} & \multirow[t]{2}{*}{$\mathrm{SEM}^{2}$} & \multirow[t]{2}{*}{ P-Value } \\
\hline & $\mathrm{CON}$ & $\mathrm{O} 1$ & $\mathrm{O} 2$ & $\mathrm{O} 3$ & & \\
\hline \multicolumn{7}{|c|}{ Phagocytic rate (\%) } \\
\hline $14 d$ & $16.56 b$ & $21.18 \mathrm{a}$ & $21.65 a$ & $24.61 a$ & 0.92 & 0.042 \\
\hline $28 d$ & $25.12 b$ & $34.47 a$ & $36.27 a$ & $39.12 a$ & 1.21 & 0.038 \\
\hline $42 d$ & $25.47 b$ & $38.37 a$ & $40.28 a$ & $41.67 a$ & 1.82 & 0.026 \\
\hline \multicolumn{7}{|c|}{ Phagocytic index } \\
\hline $14 d$ & 1.38 & 1.40 & 1.39 & 1.42 & 0.17 & 0.524 \\
\hline $28 d$ & 1.64 & 1.97 & 2.04 & 2.17 & 0.21 & 0.178 \\
\hline $42 d$ & $1.79 b$ & $2.67 a$ & $2.85 a$ & $2.95 a$ & 0.79 & 0.037 \\
\hline
\end{tabular}

${ }^{1}$ Control = basal diet; $\mathrm{O} 1, \mathrm{O}$, and 03 groups = basal diet with 50, 80, and $100 \mathrm{mg} / \mathrm{kg}$ ORI, respectively

${ }^{2}$ Standard error of the mean based on pooled estimate of variation

${ }^{a-b}$ Means within the same row that do not share a common superscript are

significantly different $(P<0.05) ; n=8$

the present study showed that ORI supplementation has no effect on WG, FI or FCR at any recorded ages in the chickens. These results were consistent with results by Zheng et al. (2016) [5], who reported that adding of ORI did not affect the growth performance of broilers. The discrepancies among our findings with other studies for WG and FI are primarily due to animal species.

Several studies have reported that antibacterial activity of oridonin should be regarded as having the promising effect in the healing of gastro-duodenal complaints [9]. Therefore, oridonin can be used as a protective additives of the gastrointestinal system of the body, but may not paly some valuable roles in the growth performance of

Table 6 Effects of ORI on the concentration of serum cytokine of broiler chickens (ng/L)

\begin{tabular}{|c|c|c|c|c|c|c|}
\hline \multirow[t]{2}{*}{ Items } & \multicolumn{4}{|c|}{ Diet Treatments $^{1}$} & \multirow[t]{2}{*}{ SEM $^{2}$} & \multirow[t]{2}{*}{$P$-Value } \\
\hline & CON & O1 & $\mathrm{O} 2$ & $\mathrm{O} 3$ & & \\
\hline \multicolumn{7}{|l|}{$14 \mathrm{~d}$} \\
\hline IL-2 & $11.37 b$ & $23.28 a$ & $25.49 a$ & $30.12 a$ & 0.62 & 0.037 \\
\hline IL-4 & $96.97 b$ & $253.47 a$ & $276.37 a$ & $337.37 a$ & 3.24 & 0.012 \\
\hline TNF-a & $214.77 b$ & $456.32 a$ & $469.87 a$ & $496.78 a$ & 4.45 & 0.027 \\
\hline \multicolumn{7}{|l|}{$28 d$} \\
\hline IL-2 & $12.07 b$ & $21.58 \mathrm{a}$ & $25.34 a$ & $29.72 a$ & 1.02 & 0.021 \\
\hline IL-4 & $103.42 \mathrm{~b}$ & $188.67 a$ & $205.67 a$ & $211.34 a$ & 3.45 & 0.019 \\
\hline TNF-a & $425.38 b$ & $675.30 \mathrm{a}$ & $692.34 a$ & $732.04 a$ & 6.72 & 0.039 \\
\hline \multicolumn{7}{|l|}{$42 d$} \\
\hline IL-2 & $14.24 b$ & $26.23 a$ & $28.37 a$ & $28.97 a$ & 0.95 & 0.019 \\
\hline IL-4 & $114.37 \mathrm{~b}$ & $190.24 a$ & 219.37a & $286.34 a$ & 1.38 & 0.031 \\
\hline TNF-a & 109.37b & $385.34 a$ & $403.37 a$ & $465.35 a$ & 7.65 & 0.047 \\
\hline
\end{tabular}

${ }^{1}$ Control = basal diet; 01,02 , and 03 groups = basal diet with 50, 80, and $100 \mathrm{mg} / \mathrm{kg}$ ORI, respectively

${ }^{2}$ Standard error of the mean based on pooled estimate of variation

${ }^{a-b}$ Means within the same row that do not share a common superscript are significantly different $(P<0.05) ; n=8$ 
broilers when broiler chickens are kept in the clean environment and provided the highly digestible diets. Additionally, the dosage and purity of oridonin, breeding density of broilers, and many other factors can be due to inconsistent results.

In our present study, no differences were observed among the ORE treatments in the relative weights of thymus, liver, pancreas or gizzard. However, the relative weights of spleen and bursa were increased in response to feeding of basal diets containing oridonin, which was in line with results of Zheng et al. (2016) [5]. The spleen and bursa are the most important immune organs in the broiler chicken body, and they can suppress immune function by various approaches and induce the status of immunosuppression in broilers. Thus, the measurement of internal immune organ weight is a common method of estimating immune status in chickens [10]. In our present study, the increased immune ability, was likely attributed to the immunosuppressive effect of oridonin [11], may also showed that oridonin can improve immune function in broilers, thus explaining the good health status of broilers in the current study.

$\mathrm{T}$ and $\mathrm{B}$ lymphocytes play central roles in immune response to any type of stress and/or aggression. Consequently, the number of $\mathrm{T}$ and $\mathrm{B}$ cells could be a fungible index of lymphocyte immunityability. Moreover, the thymus, spleen and bursa are sites of $\mathrm{B}$ and $\mathrm{T}$ cell differentiations in broilers. The relative weights of lymphoid organ are used for reflecting the immune status of birds, and changes in weight may be related with alterations in the immune function of lymphoid organs [12]. Because ORI is an immunoenhancer, it encourages faster cell proliferation and differentiation in the immune system of experimental animals. It seems that dietary ORI stimulates the $\mathrm{T}$ and $\mathrm{B}$ lymphocyte formations, proliferation, and the division, as well as activity of blood. Liu et al. (2007) found that ORI is able to accelerate proliferation of lymphocytes, and that ORI affects body's immune function and disease resistance [11].

In the present study, we chose ORI as the irritants of $\mathrm{T}$ lymphocytes, which can activate many intralymphocyte signaling pathways [13]. For the irritants, we observed an increases in immune response in the number of peripheral blood $\mathrm{T}$ and $\mathrm{B}$ cell counts. This might be associated with ORI's ability to activate $\mathrm{T}$ cells, which may be partially due to $T$ cell depletion in the thymus and the peripheral immune system. Some pharmacological studies show that oridonin is quickly removed from the circulatory system (the level of oridonin in blood was reduced by $78 \%$ within 2 h) [14]. The rapid removal of oridonin may explain the different effects of oridonin in vitro and in vivo to some extent. Additional studies will be required before fully understanding its potential applications in the modern broiler breeding.
Neutrophils, as the richest peripheral circulating immune cells, constitute the first-line defense against invading pathogens and act pivotal part in the early stages of inflammation and immune responses. Neutrophil functions, including phagocytosis, degranulation, cytokine release and neutrophil extracellular traps (NETs) formation, play critical roles in the innate immune response against infection through their ability to quickly identify and remove invading germs. Therefore, the phagocytic effect of neutrophils is an important immune parameter because it is strong connections with the clearance of pro-inflammatory necrotic tissue and cell residues.

The results showed that addition of ORI significantly increased the phagocytic index of neutrophil on day 42 , and the phagocytic rate of neutrophils of broilers in the whole experiment. We presume that this increase may also be attributed to $\mathrm{T}$ cell depletion in the peripheral blood immune system. Numerous studies have shown that ORI has an anti-inflammatory effect. ORI decreases systemic inflammation responses and the increase of phagocytosis, and may be a potential potentially novel therapeutic agent for the treatment of inflammatory disease.

The cytokine level in serum is an important index for humoral immunity in poultry. By now, it is generally known that $\mathrm{Th}_{1}$ cells excrete proinflammatory cytokines, such as TNF- $\alpha$, IL-2 and IL-12, however $\mathrm{Th}_{2}$ cells secrete anti-inflammatory cytokines, such as IL-4, IL-5, IL6 , and IL-10 [15]. In the present study, our findings show that serum TNF- $\alpha$, IL-2 $\left(\mathrm{Th}_{1}\right)$ and IL- $4\left(\mathrm{Th}_{2}\right)$ in the broilers receiving 50,80 , and $100 \mathrm{mg} / \mathrm{kg}$ of ORI were significantly lower than those in control broilers, indicating that ORI could regulate humoral immunity of broilers. In birds, few studies have investigated the immunostimulatory effect of ORI. About our present results, the lower cytokines levels produced in ORI-treated broilers is likely related to ORI's anti-inflammatory potential through the repression of T-cell immune responses [6]. Our results are similar to previous studies and further indicate that certain terpenoid compounds may play their anti-inflammatory effects through the regulation of $\mathrm{Th}_{1} / \mathrm{Th}_{2}$ cytokine secretion levels or repression of T-cell immune responses. We assume that ORI might regulate the differentiation of Th cells; however, future animal and laboratory tests should be conducted to verify potential mechanisms of action.

\section{Conclusions}

Based on the results of the present work, it was concluded that diet inclusion of ORI increases the relative weight of spleens and bursa, the number of proliferation peripheral blood $\mathrm{T}$ and $\mathrm{B}$ lymphocytes, and the phagocytic rate of neutrophils, it may also stimulate IL-2, IL-4 
and TNF-a production in broilers. Therefore, it could be concluded that dietary use of ORI as a feed additive may improve the immune function and disease resistance ability in broiler production. Further research is needed to understand and clarify the possible mechanisms involved.

\section{Abbreviations}

FCR: Feed conversion ratio; Fl: Feed intake; IL-2: Interleukin-2; IL-4: Interleukin-2; MTT: 3-(4,5-dimethylthiazol-2-yl)-2,5-diphenyltetrazolium bromide; NETs: Neutrophil extracellular traps; ORI: Oridonin; PI: Phagocytosis index; PP: Phagocytosis percentage; TNF-a: Tumor necrosis factor-a; WG: Weight gain

\section{Acknowledgements}

We would like to thank Tianyue Tang, Beibei Yuan, Fengli Zhang and Lili Yuan their skillful technical assistance for this research.

\section{Funding}

Financial support for the study and its publication was provided by the Foundation of State Key Laboratory of Animal Nutrition of China (2004DA125184f1407) and the Priority Academic Program Development of Jiangsu High Education Institutions (PAPD) (BE2010356). State Key Laboratory of Animal Nutrition of China and Priority Academic Program Development of Jiangsu High Education Institutions have given final approval of the version to be published.

\section{Availability of data and materials}

The datasets generated, used and analyzed during the current study are available from the corresponding author on reasonable request.

\section{Authors' contributions}

WQJ and ZXC designed the study and conducted the treatment phase. WT participated in study design and discussion of results. ZTY was responsible for evaluation of results and medical writing. All authors approved the manuscript.

\section{Ethics approval}

Principles of laboratory animal care were followed, and all procedures were conducted according to the guidelines of the Council for the International Organizations of Medical Sciences and the Internationla Council for Laboratory Animal Science. All the experimental procedures were approved by the Institutional Animal Care and Use Committee of the Nanjing Agricultural University (Nanjing, People's Republic of China).

\section{Consent for publication}

Not applicable.

\section{Competing interests}

The authors declare that they have no competing interests.

\section{Publisher's Note}

Springer Nature remains neutral with regard to jurisdictional claims in published maps and institutional affiliations.

\section{Author details \\ ${ }^{1}$ College of Animal Science and Technology, Nanjing Agricultural University, No. 6, Tongwei Road, Xuanwu District, Nanjing 210095, Jiangsu, People's Republic of China. ${ }^{2}$ State Key Laboratory of Animal Nutrition, NO. 2, Yuan Ming Yuan West Road, HaiDian District, Beijing 100193, People's Republic of China. ${ }^{3}$ College of Animal Science and Technology, Henan University of Science and Technology, Luoyang 471003, Henan, People's Republic of China.}

Received: 25 January 2017 Accepted: 23 January 2018

Published online: 31 January 2018

\section{References}

1. Du YF, Liu PW, Zhu H, Shi XW, Zhao CC, Wang N, et al. A sensitive analysis method for 7 diterpenoids in rat plasma by liquid chromatography electrospray ionization mass spectrometry and its application to pharmacokinetic study of Isodon Serra extract. J Chromatogr A. 2011;1218:7771-80.

2. $\quad$ Liu Z, Ouyang L, Peng $H$, Zhang WZ. Oridonin: targeting programmed cell death pathways as an anti-tumour agent. Cell Prolif. 2012:45:499-507.

3. Ming M, Sun FY, Zhang WT, Liu JK. Therapeutic effect of oridonin on mice with prostate cancer. Asian Pac J Trop Med. 2016;9(2):184-7.

4. Osawa K, Yasuda H, Maruyama T, Morita H, Takeya K, Itokawa H. Antibacterial trichorabdal diterpenes from Rabdosia trichocarpa. Phytochemistry. 1994;36: 1287-91.

5. Zheng XC, Wu QJ, Song ZH, Zhang H, Zhang JF, Zhang LL, et al. Effects of Oridonin on growth performance and oxidative stress in broilers challenged with lipopolysaccharide. Poultry Sci. 2016;95(10):2281-9.

6. Guo WZ, Zheng PG, Zhang JK, Ming L, Zhou C, Zhang SJ. Oridonin suppresses transplant rejection by depleting $T$ cells from the periphery. Int Immunopharmacol. 2013:17:1148-54.

7. National RC. Nutrient Requirements of Poultry. 9th Rev. Ed. Washington DC: Natl. Acad. Press; 1994

8. Xu Y, Xue Y, Wang Y, Feng DC, Lin ST, Xu LY. Multiple-modulation effects of Oridonin on the production of proinflammatory cytokines and neurotrophic factors in LPS-activated microglia. Int Immunopharmacol. 2009;9:360-5.

9. Kadota S, Basnet P, Ishii E, Tamura T, Namba T. Antibacterial activity of tri-chorabdal a from Rabdosia trichocarpa against helicobacter pylori. Zentralblatt Für Bakteriologie. 1997;286(1):63-7.

10. Heckert RA, Estevez I, Russek-Cohen E, Pettit-Riley R. Effects of density and perch availability on the immune status of broilers. Poultry Sci. 2002:81(4):451-7.

11. Liu J, Yang F, Zhang Y, Li J. Studies on the cell-immunosuppressive mechanism of Oridonin from Isodon serra. Int Immunopharmacol. 2007;7:945-54.

12. Cooper MD, Raymond DA, Peterson RD, South MA, Good RA. The functions of the thymus system and the bursa system in the chicken. J Exp Med. 1966;123:75-102.

13. Ding Y, Ding CY, Ye N, Liu ZQ, Wold EA, Chen HY, et al. Discovery and development of natural product oridonin-inspired anticancer agents. EurJ Med Chem. 2016;122:102-17.

14. Lou H, Gao L, Wei X, Zhang Z, Zheng D, Zhang D, et al. Oridonin nanosuspension enhances anti-tumor efficacy in SMMC-7721 cells and H22 tumor bearing mice. Colloid Surfaces B: Biointerfaces. 2011;87:319-25.

15. Romagnani S. Biology of human $\mathrm{TH}_{1}$ and $\mathrm{TH}_{2}$ cells. J Clin Immunol. 1995;15: $121-9$.
Submit your next manuscript to BioMed Central and we will help you at every step:

- We accept pre-submission inquiries

- Our selector tool helps you to find the most relevant journal

- We provide round the clock customer support

- Convenient online submission

- Thorough peer review

- Inclusion in PubMed and all major indexing services

- Maximum visibility for your research

Submit your manuscript at www.biomedcentral.com/submit
Biomed Central 